\title{
INTERthesis
}

\section{NEM ORDEM NEM PROGRESSO PARA O NOSSO TERRITÓRIO. O (DES)ORDENAMENTO TERRITORIAL NA GALIZA ${ }^{1}$}

Xoán M. Paredes ${ }^{2}$

\section{Resumo:}

A organização territorial galega é uma realidade complexa, herdeira de uma longa evolução e afectada por fortes mudanças sociais, políticas e económicas recentes que vieram a alterá-la, até o ponto de se fazer necessário um planeamento espacial reequilibrador. Este ensaio pretende apontar de forma breve, e com uma óptica de estudos post-coloniais, como isto não só não foi conseguido, senão como tentativas de ordenamento territorial contemporâneo tiveram em muitas ocasiões um efeito contrário.

Palavras chave: Galiza. Planeamento. Paróquia (freguesia). Comarca. Província.

\section{INTRODUÇÃO}

Com uma superfície que ocupa pouco mais do $5 \%$ da Península Ibérica e uma população que também partilha essa percentagem hoje em dia, a Galiza ${ }^{3}$ acolhe uns 33.000 núcleos habitados, isto é, a metade dos presentes em toda essa península sul-europeia. Estes núcleos não são só enormemente diversos, senão que estão espalhados numa topografia que é, pela sua parte, complexa e fragmentada.

Comenta-se formal e informalmente que o outro grande património galego, depois da língua, é o território. Efectivamente, o território é uma obra de arte, é algo que nos pode definir em uma só imagem, como toda paisagem cultural.

Antes de mais nada, o que é uma paisagem cultural? Este termo aparece por vez primeira com Otto Schülter em 1908, quem definiu a geografia como uma ciência da paisagem, onde era possível distinguir entre uma 'paisagem original'

\footnotetext{
${ }^{1}$ Este ensaio foi escrito em português da Galiza, seguindo o critério da Academia Galega da Língua Portuguesa (Disponível em www.academiagalega.org), adaptando unicamente algum vocabulário usado de forma local para uma melhor compreensão internacional.

${ }^{2}$ Doutor em Ordenamento territorial pela University College Cork, Irlanda. Professor no Centro de Iniciativas Culturais e Académicas em Ponte Vedra, Galiza, Espanha. E-mail: xoan@xoan.net

3 A Galiza é na actualidade um território autónomo (oficialmente "Comunidade Autónoma") com status de "nacionalidade histórica" dentro da administração do Estado Espanhol, desde 1981. No Brasil é frequentemente referida como "Galícia", embora o nome usado em português europeu é "Galiza". Ambas formas ("Galícia" / "Galiza") são válidas legalmente em território galego, sendo a última a recomendada pela Associação Galega da Língua Portuguesa e a Associaçom Galega da Língua, entre outros, e a escolha pessoal do autor.
}

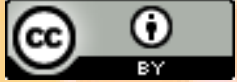


(existente antes da acção antrópica) e uma 'paisagem cultural' (criada pela cultura humana) (JAMES e MARTIN, 1981). Porém, o investigador mais influente na concretização deste conceito foi o célebre geógrafo estado-unidense Carl Sauer. Ele definiu que "a paisagem cultural está formada a partir de uma paisagem natural por um grupo cultural. A cultura é o agente, a área natural é o meio, a paisagem cultural é o resultado" (SAUER, 1925: 19-52). Reflectindo sobre o caso galego, O'FLANAGAN (1996) aplica estas ideias e conclui que é de facto uma obra colectiva, milenária no nosso caso. Segundo PAREDES (1999), o conceito de paisagem cultural pode ser definido de forma extensa como o meio modificado pelo ser humano ao longo do tempo, a combinação a longo prazo entre a acção antrópica sobre esse meio e os condicionantes físicos limitantes ou condicionantes sobre a actividade humana. É uma área geográfica - incluindo recursos naturais e culturais associados com uma evolução histórica, e que acaba por dar lugar a uma paisagem reconhecível para um grupo humano determinado, até o ponto de ser identificativo como tal para outros.

Uma paisagem cultural leva associadas normalmente uma série de divisões, limites, usos e carga simbólica que a dotam de uma continuidade que pode ser estudada e rastrejada até bem atrás no tempo, como demonstrou PENA (1994, 2010). Assim, não é estranho que a olhos estrangeiros a Galiza ainda produz a sensação de que "tudo o que [um] vê é antigo, venerável e imutável ... [Galiza] segue a apresentar as manifestações mais abundantes e variadas de um carácter próprio das que hoje podem encontrar-se na Europa Ocidental" (O'FLANAGAN, 1996: 17 e 65).

Um dos problemas sobre o que tenta fazer reflexionar este texto é o desaparecimento acelerado das bases sobre as quais essa paisagem foi construída, sem mais motivo que uma má gestão ou simples negligência, como aconteceu desde a tardia introdução do ordenamento territorial na Galiza (finais dos anos 50 do S.XX) até a actualidade, passando desde um regime ditatorial altamente centralista ${ }^{4}$

4 O Franquismo foi o regime político vigente no Estado Espanhol, e por consequência na Galiza, entre 1939 e 1975, durante a ditadura do general Francisco Franco. Foi uma época marcada por uma ideologia fortemente conservadora, isolacionista, repressora (JASPE, 2000) e com total supremacia do nacionalismo espanhol, motivos pelos quais é conhecida também como "nacional-catolicismo", com elementos do fascismo. O período de "transição" (1975-1978) deu lugar a um novo regime político e eventualmente à consecução da actual "autonomia galega" em 1981.

R. Inter. Interdisc. INTERthesis, Florianópolis, v.12, n.2, p. 95-115 Jul-Dez. 2015 
a várias legislaturas de diferente cor política durante a presente autonomia galega (BEIRAS, 1969, 1995; LAGO e LAGO, 2006; PAREDES, 2007).

Em perspectiva histórica, e acompanhando o processo de mudanças políticoadministrativas depois da marcante implantação da Coroa de Castela (centro do futuro Estado Espanhol) no antigo Reino da Galiza a finais do S.XV (GARCÍA, 1963), pode-se dizer que os chamados Séculos Escuros ${ }^{5}$ tiveram um amplo leque de aspectos negativos, mas é certo que nesse período não se brincou em excesso com a estrutura íntima do nosso território. A metrópole ficava satisfeita com as remessas de impostos e mão de obra, deixando que se lidara internamente com os níveis espaciais mais pequenos, incluídas as paróquias (freguesias), com relativa normalidade (O'FLANAGAN, 1996; LÓPEZ et al, 2013). Contudo, o fim dessa época não vem determinado necessariamente por uma melhoria das condições económicas ou políticas, senão por uma série de reformas administrativas e organizativas da própria Espanha, que pretendia copiar o novo modelo de estado centralista francês (S. XIX) (FARIÑA, 1990, 1994; CAL Y CORTINA, 1997), além de uma falsa sensação de modernidade e progresso, ao que ajudou a primeira vaga de emigração maciça a América, aligeirando a pressão demográfica e remetendo divisas.

Assim, a questão do território galego e a sua organização e gestão é um tema já velho e até pode parecer gasto, mas não por isso deixa de ser relevante por inacabado. O presente artigo está, de facto, compilado em base a uma investigação anterior que, mesmo com o passar do tempo, não deixa de ser tristemente actual. Tentará-se agora apresentar estas questões e explorar algumas possíveis soluções.

\footnotetext{
$5 \mathrm{Na}$ historiografia galega, os Séculos Escuros são a etapa que se estende desde finais do S. XV com o estabeleci5 O Franquismo foi o regime político vigente no Estado Espanhol, e por consequência na Galiza, entre 1939 e 1975, durante a ditadura do general Francisco Franco. Foi uma época marcada por uma ideologia fortemente conservadora, isolacionista, repressora (JASPE, 2000) e com total supremacia do nacionalismo espanhol, motivos pelos quais é conhecida também como "nacional-catolicismo", com elementos do fascismo. O período de "transição" (1975-1978) deu lugar a um novo regime político e eventualmente à consecução da actual "autonomia galega" em 1981. $5 \mathrm{Na}$ historiografia mento da Coroa de Castela - até o S. XVIII, com as simbólicas publicações de obras em língua galega, em território galego, por primeira vez desde a Idade Média (LÓPEZ et al, 2013).
} 
Figura 1 - A Comunidade Autónoma galega (oficial) e os limites provinciais

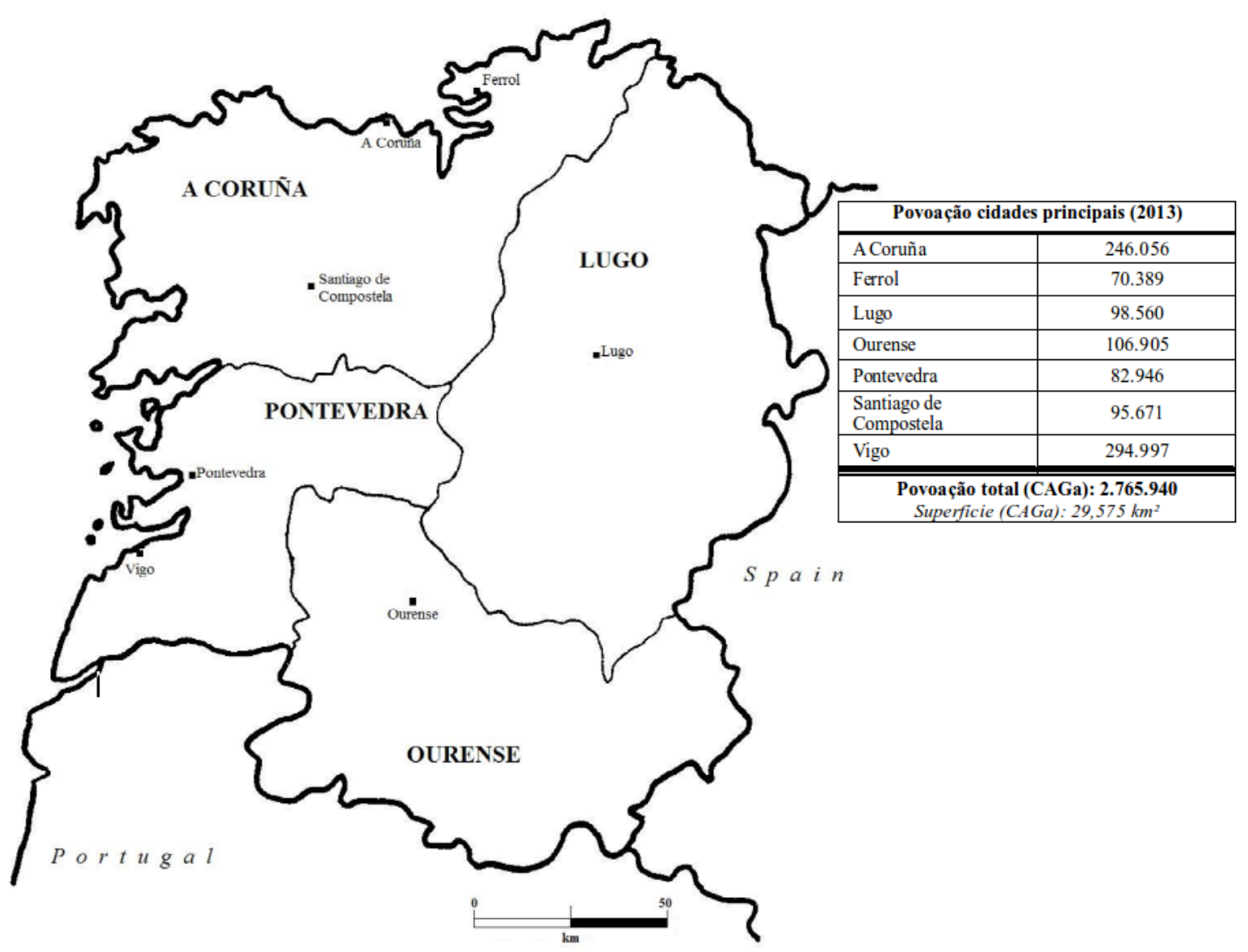

Fonte: Autor.

\section{0 (VELHO) DEBATE DA REFORMA TERRITORIAL}

$O$ movimento galeguista ${ }^{6}$ a começos do $S$. XX já andava às voltas com propostas concretas sobre possíveis reformas administrativas e territoriais, não sendo casualidade de as conclusões virem ser sempre as mesmas desde então até hoje, firmemente no S. XXI, como veremos.

CASTELAO (1944) resume as críticas que em uma primeira época provocou a reforma dos concelhos (1812) ou a reforma provincial forçada em 1833 (de sete às actuais quatro províncias), que chegou a induzir uma conflito armado em 1846 ao considerar-se a nova divisão territorial e políticas fiscais associadas gravemente

60 galeguismo é um movimento social e político de corte patriótico galego que tem como objectivo a defesa da Galiza mediante a criação de instituições próprias, promoção da sua língua e cultura e recuperação da sua soberania. Tem as suas origens a mediados do S.XIX e, organicamente, em 1916 com o estabelecimento das chamadas 'Irmandades da Fala'. Considera-se consolidado com a redacção e aprovação do Estatuto de Autonomia de 1936 (NÚÑEZ e BERAMENDI, 1995; BERAMENDI, 2007; LÓPEZ et al, 2013). Na actualidade diversas forças políticas e movimentos e associações culturais, assim como indivíduos, declaram-se publicamente como galeguistas.

R. Inter. Interdisc. INTERthesis, Florianópolis, v.12, n.2, p. 95-115 Jul-Dez. 2015 
prejudiciais para a Galiza. A seguir, este famoso autor eleva-se em voz do movimento galeguista clássico na reclamação de uma Galiza como um único território onde dentro do qual, segundo interpretação de BARBOSA (2011: internet) "houvesse comarcas e dentro das quais se desse entrada às nossas paróquias ou freguesias com personalidade jurídica própria e organização legal e administrativa".

OTERO (1965) é um outro autor referencial no estudo das jurisdições territoriais galegas em perspectiva histórica, do que se derivam formulações de possíveis alternativas à realidade administrativa imposta pelo Estado Espanhol, alheia à estrutura espacial autóctone. Assim, na Espanha as freguesias (e em grande medida as comarcas) não suportam o legado histórico e social que suportam na Galiza, tendo sido o municipalismo e o provincialismo aceites sem maior problema em geral, pois ajeitam-se correctamente à escala e padrão de assentamento e usos do espaço. Também partimos, aliás, de uma geografia física diferente que influiu na formação de paisagens culturais muito diferentes onde, como examinaremos mais à frente, tentou colocar-se um modelo único de organização territorial e, posteriormente, de planeamento.

Decerto, todas estas reflexões são repetidas ainda hoje em dia nas propostas de desmantelamento gradual da rede de Deputacións (os quatro governos provinciais galegos) e desaparição ou reestruturação dos 314 municípios existentes, com o estabelecimento das comarcas como entidade intermédia entre a democracia directa das paróquias (freguesias) e governo galego central. Como comenta BARBOSA (2011: internet):

\footnotetext{
"Uma Galiza governada por um poder único desde Compostela, com um governo galego com autoridade sobre, só, uns cinquenta e poucos Concelhos-Comarca, cada um dos quais com um número determinado de Juntas de Paróquia ... simplificaria muito as coisas e favoreceria a nossa sobrevivência como povo ... Pouparíamos grandes quantidades de dinheiro público e agilizaríamos a administração, minimizaríamos o clientelismo e o caciquismo e de passagem poderíamos solucionar muitos problemas territoriais".
}

Acaso um país de, oficialmente, pouco mais de vinte e nove mil quilómetros quadrados precisa de mais de trezentos governos locais actuando como pequenos parlamentos nacionais, burocracia incluída? Antes de continuarmos com mais análises, não é difícil adivinhar o nível de clientelismo político e guerras de interesses derivadas de tal situação. Acrescentemos agora uns tamanhos em 
superfície e população totalmente dispares, em zonas do mais variado em termos físicos, de comunicações, serviços e infraestruturas, isto é, um país desajustado (PAREDES, 2007).

O Estatuto de Autonomia da Galiza (1981, Art. 27.2 e 40.3) permite na teoria revisar o mapa paroquial e o seu status jurídico e legal, mas não alterar as províncias (fig. 1) e concelhos, que são competência do estado. Em verdade, a província é um instrumento de controlo territorial que depende em exclusiva do estado central espanhol: "é uma entidade ... para o cumprimento das actividades do Estado. Qualquer alteração dos limites provinciais deverá ser aprovada pelas Cortes Gerais" (Constituição Espanhola, 1978, Art. 141.1), e conta com importantes orçamentos próprios que são frequentemente utilizados em lutas políticas, outorgando ou retirando apoios (MÁIZ, 1997; VEIGA, 1999b). Contudo, esse poder nunca exercido da autonomia galega sobre as paróquias está em sério perigo por via de reformas legislativas recentes feitas de costas ao povo, gravemente desinformado neste tema, e que contradizem o próprio Estatuto (EVANS, 2013). O prognóstico aí é reservado.

Aliás, a alternativa das tantas vezes defendida e publicitada concentração ou fusão municipal (RODRÍGUEZ, 2004) não resolveria grande coisa, criando novas jurisdições artificiais, novos pólos e novos fluxos dos que não sabemos nada além de estudos parciais, potencialmente acelerando o despovoamento das zonas mais rurais. Fala-se do tema mas não se sabe onde é que se quer chegar, não há uma ideia de país e como se quer articular. MATO (2015: internet) sumariza:

\begin{abstract}
Em todos os casos, a proposta implica criar municípios maiores em extensão e população, mantendo estruturas idênticas dominadas por gestores/políticos- profissionais, ao serviço dos seus próprios aparatos partidários e adaptadas à nova escala de salários em função do número de habitantes ... O resultado: um afastamento ainda maior dos centros de decisão e uns municípios cada vez mais impermeáveis frente aos âmbitos de auto-organização vizinhal.
\end{abstract}

Outrossim, com o despovoamento vêm sempre associados problemas de falta de gestão directa do território, esse trabalho silencioso de preservação e manutenção que realiza o povo de forma não reconhecida ou contabilizada para a administração (CARREIRA e CARRAL, 2014); problemas que bem familiares resultam em forma de incêndios, perda de solo cultivável, biodiversidade, qualidade ambiental e paisagística, queda do turismo, desestruturação social, problemas 
psicológicos, carga sobre o sistema de saúde, lastre orçamentário para vilas intermédias insuficientemente equipadas e forçadas à improvisação, etc.

É legítimo perguntarmos se as freguesias e comarcas são, a dia de hoje, realmente relevantes desde um ponto de vista sócio-espacial, se não são a estas alturas já um outro elemento estranho na nossa cultura e no nosso território. CAL Y CORTINA (1997) afirma que a base da divisão sociológica da Galiza era a paróquia, e a municipalidade constitucional teve que 'acomodar' a sua organização territorial a esta bem-estabelecida divisão territorial galega. Mas é isso certo ainda no ano 2015? Pensemos por exemplo em áreas urbanas onde a adscrição paroquial clássica perdeu o seu significado, cidades como Vigo, com um crescimento tão rápido e desorganizado (até triplicar o seu tamanho durante o $\mathrm{S}$. $\mathrm{XX}$ ) que pulverizou o espaço sobre o que se situava (O'FLANAGAN, 1996).

Realmente, faria falta um estudo detalhado e actualizado sobre a percepção do que é considerado 'nível local', pois ainda que o concelho/município é visto mais favoravelmente desde que virou possível votar directamente pelos seus órgãos de governo (MÁIZ, 1997; VEIGA, 1999a), continua em muitos casos a ser grande de mais para o espaço vivido, isto é, dentro de um concelho rural o relacionamento formal do indivíduo é com o poder central desse espaço, embora na sua vivência diária o seu espaço de referência, de vizinhança, seja bem mais pequeno. Em situações urbanas ou semi-urbanas produz-se a mesma situação, onde o governo municipal é referência enquanto responsável do fornecimento de bens e serviços e arrecadador de impostos, mas a vivência da cidade é normalmente realizada em espaços mais pequenos, é uma cultura 'bairrista'. Pode ser, então, que muitos limites paroquiais tenham sido modificados ou até eliminados na contemporânea apropriação popular do espaço, mas isso não invalida que a sociedade galega continue a se articular de forma espontânea em unidades mais pequenas que o concelho médio. Portanto, pensar em entidades como as paróquias galegas, em uma rede devidamente reformulada, como jurisdições onde desenvolver uma democracia directa e participativa é uma opção totalmente válida a longo prazo. EVANS (2014: internet) defende este modelo como factível utilizando o exemplo das freguesias portuguesas (nomeadamente do norte, estruturalmente e de origem idêntica à galega mas com impacto político real), ou até as 
[...] quase 3.000 comunas suíças [que têm] menos de 1.000 habitantes, sendo portanto equiparáveis à nossa própria realidade territorial ... Apenas $20 \%$ das comunas suiças ... têm corporação ('parlamento') municipal, sendo que o governo se faz através do sistema de democracia directa assemblear, sem que isso seja obstáculo (mais bem tudo o contrário) para gerir de jeito eficiente e não profissionalizado a decisão sobre o extenso âmbito competencial municipal. Mesmo que com atribuições muito mais reduzidas, também na Inglaterra $90 \%$ do território está organizado em 'Concelhos Paroquiais', sendo a assembleia (parish meeting) a sua instituição fundamental.

E é que "na Inglaterra há mais de 10.000 concelhos paroquiais nos que participam gratuitamente 80.000 concelheiros [vereadores] e nos que anualmente as decisões mais importantes, incluindo os orçamentos, são tomadas na assembleia aberta de toda a vizinhança." (MATO, 2015: internet).

Em todo caso, faz falta um novo nível intermédio de relacionamento, que não pode ser a aparatosa província actual. De facto, assim como os governos municipais são vistos com frequência como um foco de disputas e conflitos políticos, mas até certo ponto toleráveis porque podem ser votados, como foi comentado, os governos provinciais (Deputacións) são directamente percebidos como construções burocráticas artificiais sem sentido (FARIÑA, 1990, 1994). Surge aí logo a comarca como esse possível nível regional galego, com todas as reservas e reconhecendo que em muitos casos a sua presença a nível popular não é homogénea, mas sim como elemento real, autóctone, e presente em grande parte do país que pode ser utilizado na coordenação das entidades locais e como áreas de planeamento sem uma excessiva burocracia (GARRIDO e LOIS, 1993). Esta burocracia poderia ser poupada, aliás, das quatro províncias existentes, na linha do anotado por BARBOSA (2011).

Os limites comarcais têm sido tradicionalmente um tema de intenso debate $\mathrm{e}$ desencontros, incluído o actual modelo oficial (PRECEDO, 1998; fig. 2), irrelevante na prática e acusado de cingir-se ao modelo provincial e municipal pré-estabelecido, na vez de rachá-lo procurando autênticas alternativas ao desequilíbrio espacial, nomeadamente no referido ao sentimento de pertença (identificação com a comarca) e optimização na gestão e partilha de recursos e infraestruturas dentro dessa comarca, isto é, actuando com um verdadeiro nível regional/intermédio útil (PAREDES, 2007). Por exemplo, as propostas mostradas nas figuras 3 e 4 contam com clara carga política entanto que desmontam o sistema vigente, mas procuram 
esse alcance trans-municipal e trans-provincial, assim como a consideração de áreas de cultura galega mas que ficam fora da "Comunidade Autónoma" administrativa, contemplando a sua voluntária incorporação a território nacional. A figura 4 é, de facto, um rascunho acessível mas ainda em elaboração.

Figura 2 - Mapa comarcal vigente (oficial) da Comunidade Autónoma galega
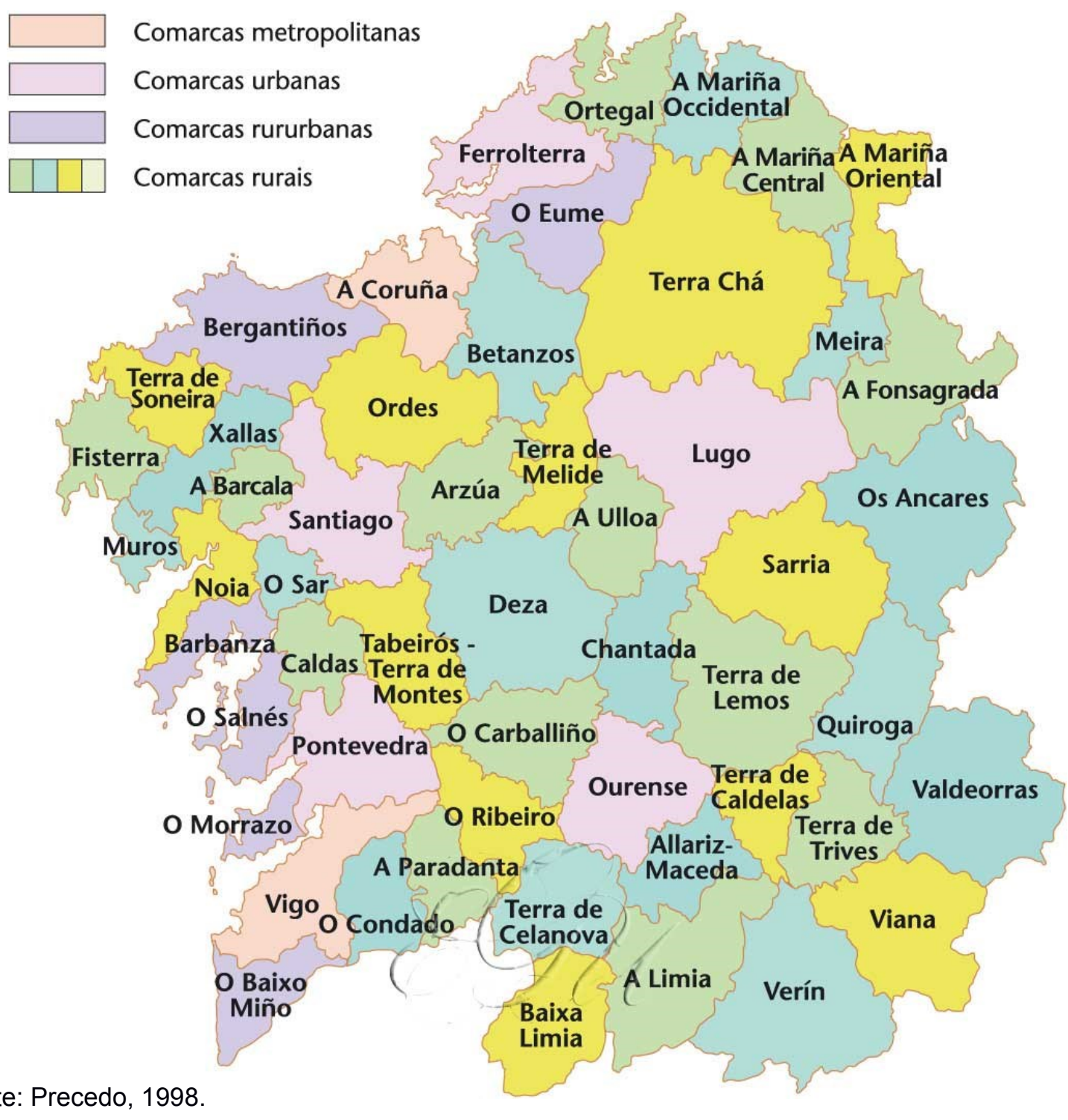

Fonte: Precedo, 1998.

\section{OS PROBLEMAS DO PLANEAMENTO E ORDENAMENTO TERRITORIAL}

A prática contemporânea de planeamento e ordenamento territorial foi introduzida relativamente tarde e mal na Galiza, em 1956, enquanto que o 
planeamento estratégico ${ }^{7}$ não apareceu até 1992 (PAREDES, 2007). Assim, o desenvolvimento e implementação de planos ou estratégias espaciais raramente tiveram resultados positivos. Em muitas ocasiões, e como já fora comentado, tal prática não tinha em conta as características reais e complexa natureza do território galego, dando frequentemente relevância à província - sob controlo estatal directo e descuidando a comarca e a paróquia (freguesia). Abordagens metodológicas deficientes ou simplesmente inexistentes vieram a aprofundar uma série de problemas estruturais, como a dicotomia costa/interior, o nomeado clientelismo político, caciquismo ou localismo, e a politização da sociedade e o território, junto a uma falta de coordenação geral perante a falta legislação adequada que funcionara como orientação.

O facto é que a Galiza não foi quem de optimizar as transformações económicas e sociais em termos de urbanização e industrialização racional, revolução tecnológica, contra-urbanização ou mesmo investir com racionalidade os fundos da União Europeia (FERRÁS, 1996, 1998). Galiza ficou constantemente flutuando no regato, mas sem se aproveitar da corrente. O câmbio rural, a modernização e a transformação urbana são uma realidade, mas a Galiza encarou estes processos de uma forma desorganizada, mesmo caótica (SOUTO, 1995; FERRÁS, 1996, 1998; PAREDES, 2007).

Pode-se dizer que o dilema fundamental reside no falhanço de estabelecer um quadro de referência, na prática, uma estratégia ou plano espacial geral capaz de coordenar e integrar todos os diferentes actores sociais, económicos e territoriais. A administração galega foi especialmente incapaz de providenciar um modelo territorial claro baseado num consenso, apesar do extenso debate académico e literatura sobre o tema, assim como a opinião popular. A nível oficial, só se encontram tímidas referências ao planeamento estratégico, às 'Leis do Solo' e PXOMs ('planos gerais de ordenamento municipal'), sendo as primeiras a sucessiva

70 planeamento estratégico estabelece que profissionais e políticos devem desenhar as linhas mestras de actuação, como no planeamento convencional, mas onde os indivíduos e comunidades devem participar no processo, tendo a responsabilidade de indicar os assuntos críticos a serem resolvidos (CAMPBELL e MARSHALL, 2000; PAREDES, 2007). Considera-se também que o planeamento para uma determinada região deve incorporar o rural e o urbano, e as suas interrelações, não como no planeamento mais tradicional onde cada zona ou uso tinha um plano específico e separado (industrial, residencial, agrícola, etc) (HAUGHTON e COUNSELL, 2004; CARREIRA e CARRAL, 2014).

R. Inter. Interdisc. INTERthesis, Florianópolis, v.12, n.2, p. 95-115 Jul-Dez. 2015 
legislação reguladora da ocupação e uso do espaço a nível galego e os segundos os planos locais, sendo comum a falta de relacionamento ou coordenação directa entre eles ou entre planos municipais e as leis superiores.

Como consequência, autoridades provinciais e municipais de toda tendência política embarcaram em agendas personalistas, agravando as práticas clientelares, desequilíbrios territoriais, construções incontroladas, especulação, desperdício de recursos e, em geral, falta de coordenação administrativa. Como disse O'FLANAGAN (1986: 52) há quase três décadas:

Há uma confusão geral sobre o que precisa reforma ... Na ausência de um plano de desenvolvimento regional integrado para a Galiza, diversas autoridades estão trabalhando para alcançar o que são realmente reformas paralelas, com a consequente duplicação e desperdiço [de recursos] grave.

Pouco mudou, pois COTO (2015: internet) afirma muito recentemente:

[na Galiza] deve ter-se em conta um território disperso, polinuclear e quase bicéfalo, que requer um esforço adicional para satisfazer necessidades de realidades não muito distintas mas contaminadas e alentadas por discursos locais, que geram sentimentos nos cidadãos que determinam as decisões políticas ... Nos últimos anos têm-se construído infraestruturas sem uma estratégia integral, sem um plano de mobilidade que abarque 0 nosso território. Infelizmente não respondem à verdadeira necessidade de articular um país mediante um tramado comum.

$\mathrm{O}$ individualismo municipal é rampante, degenerando no chamado feismo ${ }^{8} \mathrm{e}$ na degradação do património e o ambiente, onde as administrações locais e os próprios residentes chegam à conclusão de que "vale tudo" (o popular "tu vai fazendo") e transmite-se, portanto, um sentimento onde as iniciativas públicas e privadas parecem não importar-se com nada, tirando honrosas excepções.

O "problema do minifundismo", teimosamente citado nas análises clássicas do território rural galego, pode não ser o problema real na actualidade, mas sim uma falta de coordenação administrativa, legislação adaptada à nossa realidade e falta de pulo cara a dinamização social e cooperação vizinhal, mais ainda quando o rural

80 feismo é (Galipédia [http://gl.wikipedia.org/wiki/Feísmo] ; PAREDES, 2007) um conceito usado tanto a nível popular como académico que serve para designar um estilo arquitectónico ou urbanismo de traços claramente discutíveis. Trata-se de construções humanas que degradam o entorno e que chocam frontalmente com os cânones estéticos próprios do lugar. Foi definido também como "um desleixo generalizado que impera em boa parte das construções do país e que se faz especialmente patente no meio rural e naquelas zonas que sofrem os estragos da especulação urbanística" (Cultura Galega, 23/11/2004, http://www.culturagalega.org/noticia.php?id=5343).

9 O minifundismo é a prática agrícola derivada do uso e exploração de minifúndios, isto é, "explorações de pequeno tamanho [que normalmente] vêm acompanhadas duma excessiva fragmentação parcelária" (Diccionario Galego de Xeografía, 1990). Em muitos casos, essa fragmentação é derivada das sucessivas divisões hereditárias.

R. Inter. Interdisc. INTERthesis, Florianópolis, v.12, n.2, p. 95-115 Jul-Dez. 2015 
leva tempo mudando a sua fisionomia sem receber nenhuma atenção (FERRÁS, 1996; CRECENTE, 2002; CARREIRA e CARRAL, 2014).

Sem um modelo de desenvolvimento ajeitado à realidade territorial galega, os planos e políticas operarão sempre em uma estrutura territorial e administrativa que dança à volta da província e do concelho, onde a província não tem razão de ser e os concelhos são muitas vezes simplesmente incapazes de cumprirem com as suas funções e tarefas, ainda que quiseram (AMEIXEIRAS, 1999; PINO, 2001). O desprezo pela comarca e a paróquia, ou simplesmente por um nível intermédio válido, condena a muitas actuações ao fracasso desde um princípio, pois têm que funcionar num sistema que precisa todo ele de um profundo reajuste.

\section{CONCLUSÃO}

E continuaremos falando do mesmo? Isso parece, até alcançarmos algum tipo de acordo sobre um modelo territorial preferido, tanto a nível popular como académico, que deve ser proposto como o objectivo a alcançar, embora seja um ideal, mas deve existir. Devem-se alcançar compromissos políticos sólidos, com uma visão de futuro a vários mandatos. Só então, e com uma referência clara, será verdadeiramente possível desenvolver acções de ordenamento territorial e planeamento reais. Até então, qualquer tentativa de desenho, desenvolvimento ou implementação de estratégias espaciais continuará a apresentar eivas, com directrizes a serem aplicadas em uma estrutura administrativo-territorial defeituosa per se, e daqui a alguns anos escreveremos sobre como perdemos a Galiza de entre as mãos, como uma presa de areia.

É absolutamente necessário e urgente (pois uma vez encetado o processo vai requerer ainda de muito tempo e trabalho) compaginar a racionalização entre a reforma da nossa estrutura territorial e as novas políticas adaptadas a esse território, planificando para a gente, não para os edifícios ou simples obras públicas (GANS, 1969). É precisa uma visão global e adaptações regionais e locais, com flexibilidade e compreendendo de forma íntima a idiossincrasia do País.

Vai-se revelando a evidência de que o problema é que a quem lhe deveria importar não lhe importa. Ou não lhe importa ou não sabe ou não quer, o qual é tudo igualmente assustador. Por trás de toda casa a tijolo despido, parque industrial 
redundante em zona rural com blocos de apartamentos incluídos ou chalés da montanha suíça ${ }^{10}$ a pé de praia, há um arquitecto ou arquitecta que o desenha, um cargo político que o permite e uma corporação que o faz valer. Existe um governo galego que, independentemente dos desastres cometidos durante a Ditadura Franquista (ver nota a rodapé 3) e dantes, deveria ter-se esforçado nas suas diferentes encarnações desde 1981 em criar uma política séria e estrita de ordenamento territorial, do nacional ao local, esforçada em eliminar o feismo, estético e funcional, em rachar com as redes de influências que drenam os recursos públicos e facilitam a anarquia urbanística. Em definitiva, criar um modelo territorial que serva de guia para sabermos cara onde queremos ir, onde vemos a Galiza de aqui a $5,10,15,20$ anos ou além. Se queremos, e como, conservar e projectar a nossa milenar paisagem cultural.

É um debate onde todos e todas temos voz. Mas isso requer valentia institucional, e um bocado de ideia. Propostas e exemplos há-os (FERRÁs e SOUTO, 2002; PAREDES, 2007). Vontade? Ou dito doutra forma, seriam possíveis ou permitidas tais reformas no marco do Estado Espanhol? Permitiria esse Estado o desmantelamento das suas estruturas territoriais de referência em território galego? Que seria preciso politicamente para chegarmos a tal cenário? Pensemos em como os principais partidos operantes na política estatal espanhola são absolutamente contrários a tal tipo de mudança profunda, pois suporia um desajuste na própria estrutura desse Estado (AJA, 1999; AMEIXEIRAS, 1999). Como opção, poderia um hipotético Estado Galego independente garantir as reformas com sucesso? Suporia a reforma uma ruptura factual definitiva com a lógica territorial e administrativa espanhola (tão divergente da galega)? E todavia, pode a paisagem cultural galega continuar subsistindo na Espanha ou é precisa uma abordagem do problema muito mais abrangente e audaz que tudo o tentado até o de agora?

10 Os "chalés suíços" ou "de indianos" são nomes pejorativos usados popularmente para casas unifamiliares aparatosas, normalmente construídas por emigrantes retornados da Europa ou América, copiando os estilos do país de origem, com a consequente quebra visual na paisagem autóctone.

R. Inter. Interdisc. INTERthesis, Florianópolis, v.12, n.2, p. 95-115 Jul-Dez. 2015 
Figura 3 - Algumas propostas de regionalização para a Galiza (I)

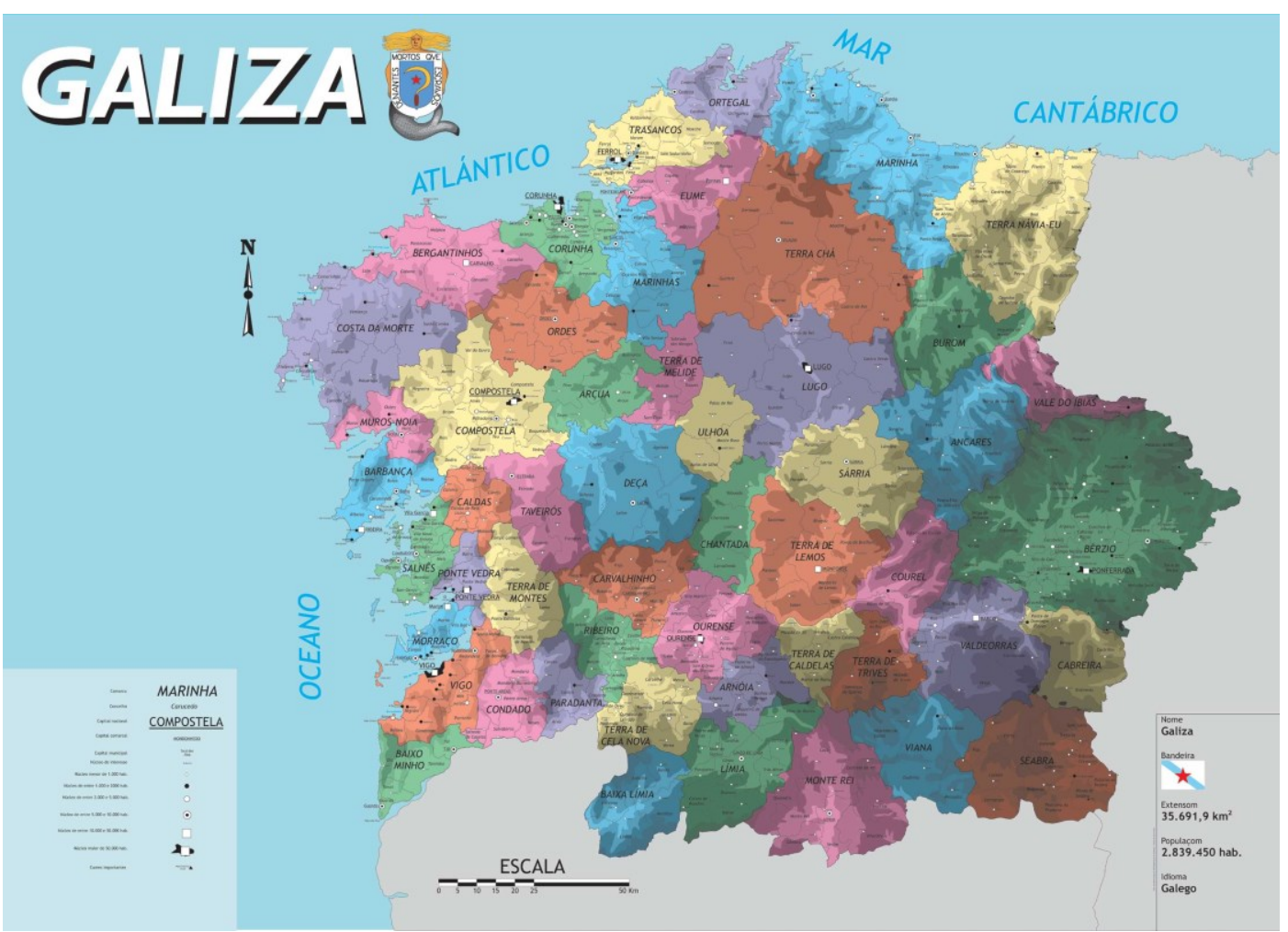

Fonte: NÓS-UP, 2006 (Disponível em: www.nosgaliza.org), extinto partido da esquerda independentista galega.

R. Inter. Interdisc. INTERthesis, Florianópolis, v.12, n.2, p. 95-115 Jul-Dez. 2015 
Figura 4 - Algumas propostas de regionalização para a Galiza (II)

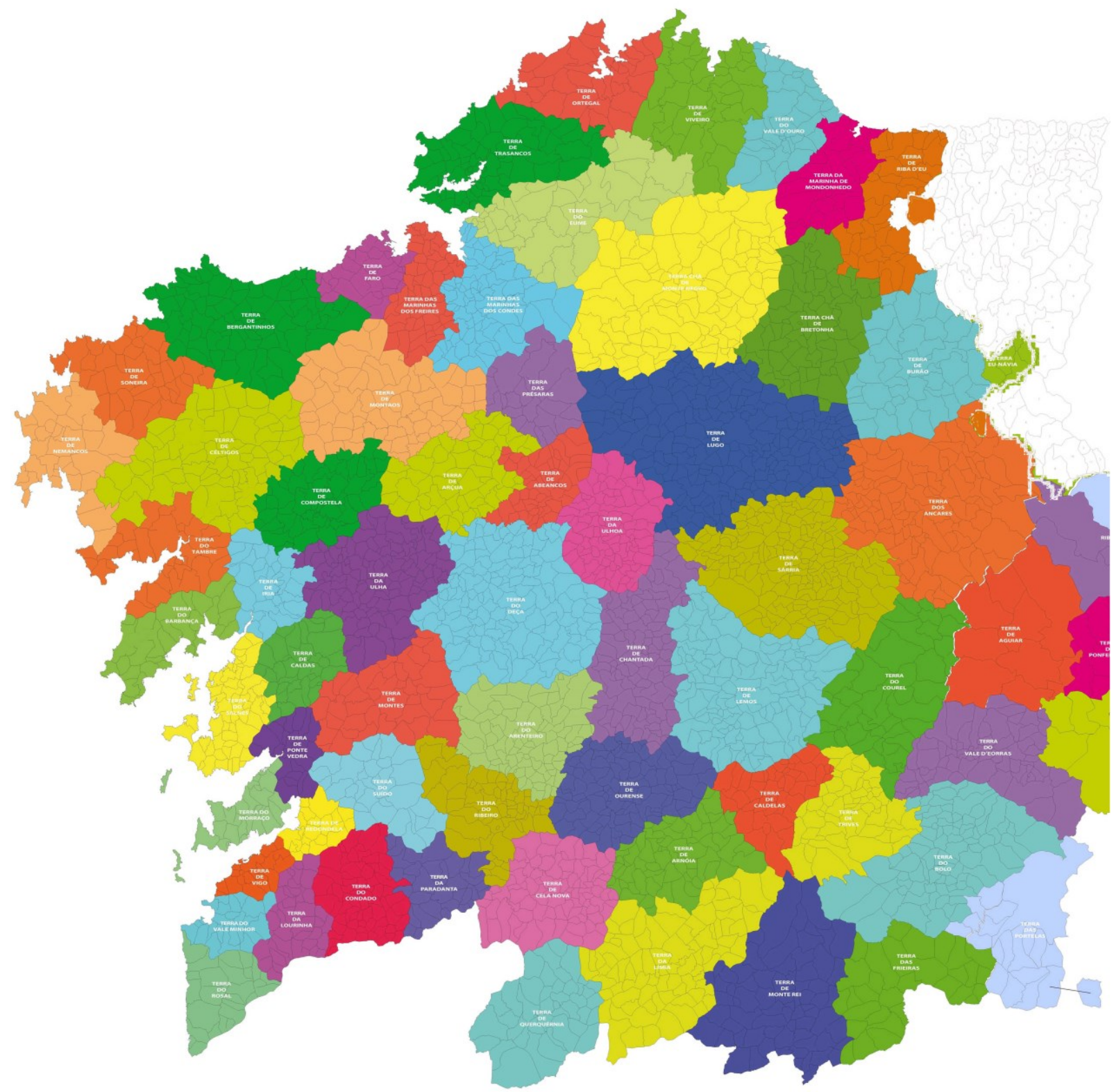

Fonte: Partido da Terra, 2015 (documento de trabalho ainda em elaboração fornecido directamente ao autor, (Disponível em www.partidodaterra.net), partido político ruralista e ecologista galego, com ideário de democracia directa e soberania integral, entre outros aspectos.

R. Inter. Interdisc. INTERthesis, Florianópolis, v.12, n.2, p. 95-115 Jul-Dez. 2015 


\title{
NEITHER ORDER NOR PROGRESS FOR OUR TERRITORY. THE (LACK OF) TERRITORIAL MANAGEMENT IN GALICIA
}

\begin{abstract}
:
The Galician territorial structure is a complex reality, heir of a long evolution and influenced by intense social, political and economical forces that resulted in drastic alterations. Thus, spatial planning was required to readjust such situation. This essay attempts to briefly point out (from a perspective of post-colonial studies) how this has simply failed, but also how contemporary territorial management practices caused further negative effects in many occasions.
\end{abstract}

Keywords: Galicia. Planning. Parish. Shire (county/region). Province.

\section{NI ORDEN NI PROGRESO PARA NUESTRO TERRITORIO. LA (DES)ORDENACIÓN TERRITORIAL EN GALICIA}

\section{Resumen:}

La organización teritorial gallega es una realidad compleja, heredera de una larga evolución y afectada por fuertes cambios sociales, políticos y económicos recientes que acabaron por alterarla, hasta el punto de hacerse necesaria una planificación territorial reequilibradora. Este ensayo pretende apuntar de forma breve, y con una óptica de estudios post-coloniales, como ésto no tan sólo no fue conseguido, sino como tentativas de ordenación territorial contemporánea tuvieron en muchas ocasiones un efecto contrario.

Palabras clave: Galicia. Planificación. Parroquia. Comarca. Provincia. 


\section{REFERÊNCIAS}

ADAMS, D. Urban planning and the development process. London: UCL Press Limited, 1995.

AJA, E. El Estado Autonómico. Federalismo y hechos diferenciales. Madrid: Alianza Editorial, 1999.

AMEIXEIRAS, P. Territorio maltratado: o que os partidos non se atreven a afrontar. Tempos Novos, Compostela, n. 24, p. 23-27, 1999.

BARBOSA ÁLVARES, J.M. Sobre uma possível reforma territorial. Desperta do Teu Sono, 2011. Disponível em: http://despertadoteusono.blogspot.com.es/2011/05/sobre-uma-possivel-reformaterritorial.html Acesso em: 12 Fev. 2015.

BATTERBURY, S.C.E. Evaluating policy implementation: the European Union's small and medium sized enter policies in Galicia and Sardinia. Regional Studies, v. 3, n. 16, p. 861-876, 2002.

BAUM, H.S. Planning theory as political practice. Society, n. 26, p. 35-42, 1988.

BEIRAS, X.M. O problema da planificación en Galiza. In: Beiras et al. (coord.) Introdución á economía galega de hoxe. Vigo: Galaxia, 1969, p. 155-187.

BEIRAS, X.M. O atraso económico da Galiza. Compostela: Laiovento, 1995.

BERAMENDI, J.G. De provincia a nación: Historia do galeguismo político. Vigo: Xerais Universitaria, 2007.

CAL Y CORTINA, R.M. Nacimiento y consolidación del municipio constitucional en Galicia. A Coruña: Deputación da Coruña, 1997.

CAMPBELL, H.; MARSHALL, R. Moral obligations, planning, and the public interest. Planning and Design, London: Pion, v. 27, n. 2, p. 297-312, 2000.

CARREIRA PÉREZ, X.C. e CARRAL VILARIÑO, E. O pequeno é grande. 
Agricultura familiar como alternativa. 0 caso galego. Compostela: Através Editora, 2014.

CASTELAO, A.D.R. Sempre en Galiza. Buenos Aires: Artes Gráficas Bartolomé U., 1944.

CHANTADA ACOSTA, J.R.; HERNÁNDEZ BORGE, J. La división territorial de Galicia y su evolución. X Reunión de Estudios Regionales, León, p. 765-784, 1984.

CRECENTE, R. et al. Economic, social and environmental impact of land consolidation in Galicia. Land Use Policy, v. 19, n. 2, p. 135-147, 2002.

COTO, C.F. No tenemos un plan. La Voz de Galicia, 2015. Disponível em: http://www.lavozdegalicia.es/coruna/2015/01/11/0003 201501H11C4993.htm Acesso em 19 Fev. 2015.

DARKE, R.; MASON, R.; ZETTER, R. The role of elected members in plan making and development control. London: Royal Town Planning Institute, 1997.

EVANS PIM, J. Uma Europa das paróquias. Diário Liberdade, 2014. Disponível em: http://www.diarioliberdade.org/galiza/institucional/46387-uma-europa-daspar\%C3\%B3quias.html Acesso em 14 Fev. 2015.

EVANS PIM, J. Morte civil. A condenação da paróquia. Diário Liberdade, 2013. Disponível em:

http://www.diarioliberdade.org/galiza/batalha-de-ideias/36506-morte-civil-acondena\%C3\%A7\%C3\%A3o-da-par\%C3\%B3quia.html Acesso em 14 Fev. 2015.

FARIÑA JAMARDO, X. As deputacións provinciais galegas: onte e hoxe II. Fegamp, n. 7 , p. 60-66, 1994b.

FARIÑA JAMARDO, X. As deputacións provinciais galegas: onte e hoxe I. Fegamp, n. 6 , p. 24-29, $1994 a$

FARIÑA JAMARDO, X. Os Concellos Galegos. A Coruña: Fundación Pedro Barrié de la Maza, 1990, 
FERRÁS SEXTO, C.; SOUTO GONZÁLEZ, X.M. Cidade Atlántica e organización territorial en Galicia. Grial, Compostela, v. XL, n. 155, p. 507-527, 2002.

FERRÁS SEXTO, C. A Contraurbanización: un achegamento teórico e estudio de casos en Irlanda, España e México. Compostela: Universidad de Guadalajara (México) - Universidade de Santiago de Compostela - Xunta de Galicia, 1998.

FERRÁS SEXTO, C. Cambio rural na Europa Atlántica: os casos de Irlanda e Galicia, 1970-1990. Compostela: Universidade de Santiago de Compostela - Xunta de Galicia, 1996.

FORESTER, J. Critical theory, public policy and planning practice: toward a critical pragmatism. Albany: State University of New York Press, 1993.

GANS, H.J. Planning for people, not buildings. Environment and Planning, n. 1, p. 33-46, 1969.

GARCÍA ÁLVAREZ, R. Contribución gallega a la formación de Castilla. Grial, Compostela, n. 2, p. 135-142, 1963.

GARRIDO FARALDO, S.; LOIS GONZÁLEZ, R.C. La comarcalización en Galicia, entre la necesidad y el caos. Actas deI XIII Congreso Nacional de Geografía, Universidad de Sevilla, p. 249-253, 1993.

HAUGHTON, G.; COUNSELL, D. Regions, spatial strategies and sustainable development. London: Routledge, 2004.

HEBBERT, M. Spain: a centre-periphery transformation. In: Hebbert and Hansen (ed.) Unfamiliar territory: The reshaping of European Geography. Aldershot: Avebury Press, 1990, p. 117-138.

JAMES, P.E.; MARTIN, G. All possible worlds: A history of geographical ideas. New York: John Wiley\&Sons, 1981.

JASPE, A. The Military Uprising of 1936 and the Repression in Galicia. Galician Review, University of Birmingham, v. 3-4, p. 77-102, 2000. 
KYMLICKA, W. Nacionalismo minoritario dentro de las democracias liberales. In: García y Lukes (ed.) Ciudadanía: justicia social, identidad y participación. Madrid: Siglo XXI, 1999, p. 127-157.

LAGO, I.; LAGO PEÑAS, S. Vinte e cinco anos de Autonomía en Galiza:

mudanzas políticas e económicas. Compostela: Escola Galega de Administración Pública, 2006.

LÓPEZ CARREIRA, A. et al. Historia de Galicia. Vigo: Xerais, 2013.

MÁIZ, R. Desconfianza e poder persoal, os mecanismos elementais do clientelismo politico. A Trabe de Ouro, n. 31, p. 299-317, 1997.

MATO, I. Fusionar ou desagregar. Galicia Confidencial, 2015. Disponível em: http://www.galiciaconfidencial.com/nova/23221-fusionar-ou-desagregar Acesso em 19 Mar. 2015.

NÚÑEZ SEIXAS, X.M.; BERAMENDI, J.G. O nacionalismo galego. Vigo: A Nosa Terra, 1995.

O'FLANAGAN, P. Xeografía Histórica de Galicia. Vigo: Xerais, 1996.

O'FLANAGAN, P. Development problems, regional planning and its implications for Atlantic Iberia. Galway: Cópia pessoal da palestra fornecida pelo autor dos fundos da Offprint Collection, Dept. Geography, National University of Ireland, Cork, 1986.

OTERO PEDRAYO, R. A aldea galega no seu decorrer histórico. Grial, Compostela, n. 8, p. 133-150, 1965.

PAREDES, X.M. Territorial management and planning in Galicia: from its origins to end of Fraga administration, 1950s - 2004. Dissertação de MPhil- Dept. of Geography, National University of Ireland, Cork, 2007.

PAREDES, X.M. Bases do Atlantismo Europeo Galego. Unha visión desde a Xeografía Cultural e Histórica. Tese de Licenciatura - Depto. de Xeografía, Universidade de Santiago de Compostela, Compostela, 1999. 
PENA GRANHA, A. Narón. Un concello con historia de seu. Vol I. Concello de Narón, 2010,

PENA GRANHA, A. O territorio e as categorías sociais na Gallaecia antiga: un matrimonio entre a Terra (Treba) e a Deusa (Mater). Anuario Brigantino, n. 17, p. 33-78, 1994.

PINO VICENTE, D. Vertebrar o territorio. Tempos Novos, Compostela, n. 44, p. 2025, 2011.

PRECEDO LEDO, A. Comarcas de Galicia. Compostela: Xunta de Galicia - USC, 1998.

RODRÍGUEZ GONZÁLEZ, R. (dir.) Os concellos galegos para o S. XXI. Un modelo aplicativo: $O$ Concello de Deza, utopía ou viabilidade? Compostela: Universidade de Santiago de Compostela, 2004.

SAUER, C. The morphology of landscape. University of California Publications in Geography, n. 22, p. 19-54, 1925.

SOUTO GONZÁLEZ, X.M. Xeografía humana. Vigo: Galaxia - Biblioteca da Cultura Galega, 1995,

VEIGA ALONSO, X.R. Tradución do clientelismo: historia dos parentes e dos amigos. Tempos Novos, Compostela, n. 24, p. 38-41, 1999b

VEIGA ALONSO, X.R. Do 'candidato oficial' ao 'goberno amigo', ou a permanente actualidade do clientelismo político, unha análise desde a historia. A Trabe de Ouro, n. 40, p. 493-511, 1999a.

Artigo

Recebido em 04 de maio de 2015

Aceito em 20 de novembro de 2015 